https://www.journal-imab-bg.org

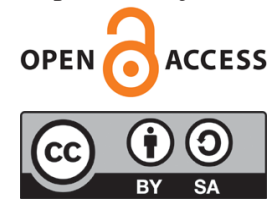

Original article

\title{
STUDY OF SOME PHYSIOLOGICAL INDICA- TORS OF THE RESPIRATORY SYSTEM AND RE- LATED ANTHROPOMETRIC DATA IN PERSONS TRAINING FOR MARINE PROFESSIONALS
}

\author{
Dimitar Stavrev ${ }^{1}$, Piareta Nikolova ${ }^{2}$, Dobrinka Doncheva ${ }^{2}$, Velislava Raynova ${ }^{3}$ \\ 1) Department of Disaster medicine and marine medicine; Medical University \\ - Varna, Bulgaria \\ 2) Department of Physiology and Pathophysiology, Medical University - Varna, \\ Bulgaria \\ 3) Student - Faculty of Medicine, Medical University - Varna, Bulgaria.
}

\begin{abstract}
The normal functioning of the respiratory system is a leading factor, both for the survival of people caught in an aquatic environment in a marine casualty and for the effectiveness of the assistance activities. In view of this, in 2020 a team of researchers from Varna Medical University, the Naval Academy Varna and the Bulgarian Red Cross set out to study some physiological respiratory parameters and related anthropometric data of 51 individuals, 41 men and 10 women aged between 17 and 48 years of age. The subjects were divided into two groups: 1) trainees in the water rescue courses conducted at BRCVarna and 2) 1st - year students of the Naval Academy. All participants in the study are non-smokers. The examination of the respiratory indicators is performed according to a standardized methodology with the same spirometer, which is able to measure and register over 30 indicators. Of these, three were analyzed in the present study: forced expiratory volume for $1 \mathrm{~s}\left(\mathrm{FEV}_{1}\right)$, forced vital capacity (FVC), and their FEV 1 /FVC percentage (Tiffeneau index). The results show that, according to anthropometric data, FVC and FEV1 are higher in water rescue trainees than in Naval Academy cadets. The Tiffeneau index is higher than the reference values of the participants in both study groups, but the results are better in the group of naval cadets. As far as the functional capabilities of the respiratory system are essential for the activity of marine professionals, it can be assumed that the high results obtained from the spirometric examination of the participants from both groups are a prerequisite for higher efficiency of rescue operations and improvement of their personal safety. when working in a marine environment. The prospect is that after collecting a statistically significant amount of data combined with results obtained from other types of functional tests, to create better safety practices for people who are professionally engaged in maritime activities.
\end{abstract}

As far as the functional capabilities of the respiratory system are essential for the activity of marine professionals, it can be assumed that the high results of the spirometric study in all study participants are a prerequisite for improving both their personal safety when working in the marine environment and for higher efficiency and success of rescue operations. The perspective is, after collecting a statistically significant volume of data and in combination with other functional studies, to create good practices to improve the safety systems of people in contact with the marine environment.

Keywords: marine medicine, marine safety, functional assessment of breathing, respiratory performance indicators,

\section{INTRODUCTION}

Exposure to aquatic environments often poses serious risks to human health $[1,2]$. Water injury is a problem that cannot be definitively solved and presupposes the regulation of every maritime activity. Efforts to control as much as possible the risk factors that inevitably arise when working in the aquatic environment are aimed at reducing health problems and protecting human health.

One of the important conditions for reducing the number of water accidents when working in the marine environment is that all persons professionally engaged in maritime activities, as well as those trained as marine professionals, are completely healthy - in the good physical condition and good mental health. Smoking, the use of psychotropic drugs, the high percentage of adipose tissue in the body, fatigue and other harmful habits hide potential risks of accidents at work in the marine environment and/or rescue operations [1,3]. It is known that in the aquatic environment there are changes in the course of a number of physiological processes - there are biomechanical problems associated with movement, changes in the mechanisms of thermoregulation and energy consumption, in the cardiovascular system, nervous system and especially in respiration [4]. The aquatic environment exerts strong mechanical pressure on the chest, increasing the aerodynamic drag resistance, which counteracts the expansion of the lungs. All these changes are espe- 
cially pronounced in extreme situations, where lifeguards expend much more muscular strength and energy. Based on the literature data on the functional changes that occur in the body when working in the marine environment $[1,4]$, it is believed that better physical development of marine professionals and more efficient processes of respiration and gas exchange, are a key factor for success in rescue operations and are important for increasing the safety of their activities.

In 2019-2020, a team from Medical University Varna, Bulgarian Red Cross and the Naval Academy began work on developing a model for functional assessment of the respiratory system and musculoskeletal system in marine professionals in order to improve their personal safety and efficiency of their work.
The aim of the present study, as part of the developed model, is to measure and analyze basic physiological indicators of the respiratory system and to determine related anthropometric data for assessment of respiratory function in persons training for marine professionals.

\section{METHOD}

The survey was conducted in the first half of the year 2020. The survey involved 51 people whose professional development is related to the marine environment - 41 men and 10 women aged between 17 and 48. Participants are divided into two comparable groups - 26 water rescue trainees in the Bulgarian Red Cross system and 25 cadets from the Naval Academy (Table 1).

Table 1. Main groups and distribution of the participants by number, age and sex.

\begin{tabular}{|l|c|c|c|c|}
\hline Participants & Age & Total number & Men & Women \\
\hline Bulgarian Red Cross water rescue trainees & $17-48$ & 26 & 22 & 4 \\
\hline Cadets from the Naval Academy & $17-23$ & 25 & 19 & 6 \\
\hline
\end{tabular}

The distribution by sex shows that in both groups, the number of men is higher. From the group of lifeguards, there are 22 men $(84.6 \%)$ and 4 women $(15.4 \%)$. Among the cadets from Naval Academy, there are 19 men $(76 \%)$ and 6 women (24\%). All participants were non-smokers.

The study of the indicators of pulmonary ventilation is performed by the method of spirometry. For the purpose, a modern spirometer of a new generation was used, which has the pulse oximeter function. The device is able to measure and register over 30 respiratory parameters, and the flow/volume curve is displayed on the screen in real-time. For the correct interpretation of the results, the device compares the measured values with the so-called predicted values, which are calculated on the basis of the previously entered anthropometric data for each participant. The evaluation of the spirometric test is always performed on the best result. For the correct conduct of the test, it is necessary for the participants to be completely healthy, rested and to provide full assistance in the re- search. To avoid the risk of transmitting an infection, each participant uses an individual disposable mouthpiece when performing the spirometric test.

All subjects are included in the study voluntarily, for which they have previously given their written consent. All participants were informed about the nature, risks and expected benefits of the study.

Seventeen spirometric indicators were registered by spirometric tests. Of these, three were analyzed in the present study: forced expiratory volume for $1 \mathrm{~s}\left(\mathrm{FEV}_{1}\right)$, forced vital capacity (FVC) and their percentage $\mathrm{FEV}_{1} /$ FVC (Tiffeneau index) [5, 6].

\section{RESULTS}

The results of the study are presented in Tables 2, 3 and 4.

Table 2 presents the anthropometric indicators - average height and weight and the range of their fluctuations in men and women from the two studied groups.

Table 2. Anthropometric indicators - height and weight in men and women from the group of lifeguards and the group of cadets from Naval Academy.

\begin{tabular}{|c|c|c|c|c|}
\hline \multirow[t]{2}{*}{ Groups } & \multicolumn{2}{|c|}{ Average height (cm) } & \multicolumn{2}{|c|}{ Weight (kg) } \\
\hline & Men & Women & Men & Women \\
\hline Bulgarian Red Cross water rescue trainees & $\begin{array}{c}183.1 \\
(172-198)\end{array}$ & $\begin{array}{c}172 \\
(167-176)\end{array}$ & $\begin{array}{c}78.5 \\
(60-105)\end{array}$ & $\begin{array}{c}68 \\
(57-79)\end{array}$ \\
\hline Cadets from the Naval Academy & $\begin{array}{c}179.7 \\
(170-193)\end{array}$ & $\begin{array}{c}169 \\
(150-181)\end{array}$ & $\begin{array}{c}74.2 \\
(60-105)\end{array}$ & $\begin{array}{c}59 \\
(52-66)\end{array}$ \\
\hline
\end{tabular}


Table 3 show the values of the main spirometric indices - FVC, FEV 1 and their percentage $\left(\mathrm{FEV}_{1} / \mathrm{FVC}^{\circ}\right)$ in the group of water rescue students at the Bulgarian Red Cross and the group of cadets from the Naval Academy.

Table 3. Spirometric indices - FVC, $\mathrm{FEV}_{1}$ and their percentage (FEV $\left./ \mathrm{FVC} \%\right)$ in the group of water rescue students at the Bulgarian Red Cross and the group of cadets from the Naval Academy.

\begin{tabular}{|l|c|c|c|c|c|c|c|c|c|}
\hline \multirow{2}{*}{ Groups } & \multicolumn{3}{|c|}{ FVC (L) } & \multicolumn{3}{c|}{ FEV $_{1}(\mathrm{~L})$} & \multicolumn{3}{c|}{ FEV $/ \mathrm{FVC}^{(\%)}$} \\
\cline { 2 - 10 } & Average & Max & Min & Average & Max & Min & Average & Max & Min. \\
\hline $\begin{array}{l}\text { Bulgarian Red Cross } \\
\text { water rescue trainees }\end{array}$ & 5.15 & 6.71 & 3.71 & 4.66 & 5.78 & 3.63 & 91.23 & 100.0 & 75.05 \\
\hline $\begin{array}{l}\text { Cadets from the Naval } \\
\text { Academy }\end{array}$ & 4.51 & 6.03 & 2.69 & 4.22 & 5.60 & 2.55 & 93.93 & 100.0 & 80.10 \\
\hline
\end{tabular}

Table 4 shows the values of $\mathrm{FVC}, \mathrm{FEV}_{1}$ and $\mathrm{FEV}_{1} / \mathrm{FVC}(\%)$ separately in men and women in the two study groups.

Table 4. Spirometric indexes - FVC, $\mathrm{FEV}_{1}, \mathrm{FEV}_{1} / \mathrm{FVC}(\%)$ for men and women from the group of lifeguards and the group of naval cadets.

\begin{tabular}{|c|c|c|c|c|c|c|c|}
\hline \multirow[t]{2}{*}{ Groups } & \multirow[t]{2}{*}{ Measured values } & \multicolumn{2}{|c|}{ FVC (L) } & \multicolumn{2}{|c|}{$\mathrm{FEV}_{1}(\mathrm{~L})$} & \multicolumn{2}{|c|}{$\mathrm{FEV}_{1} / \mathrm{FVC}(\%)$} \\
\hline & & Men & Women & Men & Women & Men & Women \\
\hline \multirow{3}{*}{$\begin{array}{l}\text { Bulgarian Red Cross } \\
\text { water rescue trainees }\end{array}$} & Average & 5.33 & 4.13 & 4.78 & 3.98 & 90.26 & 96.55 \\
\hline & Max & 6.71 & 4.83 & 5.78 & 4.39 & 100.0 & 100.0 \\
\hline & Min & 4.36 & 3.71 & 3.94 & 3.63 & 75.05 & 90.90 \\
\hline \multirow{3}{*}{$\begin{array}{l}\text { Cadets from the } \\
\text { Naval Academy }\end{array}$} & Average & 4.66 & 4.06 & 4.35 & 3.78 & 93.93 & 93.92 \\
\hline & Max & 6.03 & 5.18 & 5.60 & 5.07 & 100.0 & 100.0 \\
\hline & Min & 3.10 & 2.69 & 2.55 & 2.66 & 81.40 & 80.10 \\
\hline
\end{tabular}

\section{DISCUSSION}

The data, presented in table 2, shows that the anthropometric indicators - height and weight have higher values in men and women from the group of lifeguards compared to men and women in the group of cadets from the Naval Academy. It is noteworthy that the variations in height in female cadets are much larger $(150-181 \mathrm{~cm})$ compared to women in the group of lifeguards (167-176 $\mathrm{cm})$. As the functional indicators characterizing the activity of the respiratory system depend on the anthropometric data and sex of the subjects [4], it is possible to assume that higher anthropometric indicators in the group of lifeguards are a prerequisite for larger lung volumes and capacities and in general for better lung ventilation

The data of the spirometric examination presented in table. 3 shows that in accordance with the anthropometric indicators, FVC has higher values in the group of lifeguards than in the group of naval cadets. The measured average value for the cadets from the Naval Academy is $87.6 \%$ of that of the water rescuers, and the maximum FVC and the minimum FVC for the cadets are $89.9 \%$ and $72.5 \%$ of those of the water rescuers, respectively.

$\mathrm{FEV}_{1}$ also has higher values in lifeguards compared to naval cadets (Table 3). The differences between the two groups, presented in percentages, show that in the cadets from the Naval Academy the average, the maximum and minimum value of $\mathrm{FEV}_{1}$ are respectively $90.5 \%, 96.8 \%$ and $70.2 \%$ of those of the lifeguards.

From table 3 it can be seen that the percentage ratio $\mathrm{FEV}_{1} / \mathrm{FVC}$ (Tiffeneau index) is within normal limits, reaching higher than the reference values (maximum $100 \%$ ) in the participants of both study groups. However, when comparing the groups, the data show that the values of this indicator are higher in the group of naval cadets. The Tiffeneau index is known to be used to clinically assess airway restriction [4]. In our opinion, the obtained higher results (calculated on the basis of the measured spirometric indices) in the persons of both groups show on the one hand the very good physical development of all participants in the study, and on the other hand are a prerequisite for high efficiency of pulmonary ventilation and respiratory features in general.

When comparing the spirometric indicators according to the sex of the subjects, it is seen that the men from the group of lifeguards have higher values of FVC and $\mathrm{FEV}_{1}$ compared to the men from the group of naval cadets (Table 4). In women, the established trend is maintained - FVC and FEV 1 are higher in women lifeguards compared to women cadets from the Naval Academy, but higher maximum values of both indicators were measured in women cadets (Table 4). The maximum FVC and maximum $\mathrm{FEV}_{1}$ in women in the group of lifeguards are 
$93.2 \%$ and $86.4 \%$, respectively, compared to those of female cadets. In our opinion, insofar as anthropometric data determine the size of the studied respiratory parameters, it is possible that the higher maximum values of FVC and $\mathrm{FEV}_{1}$ in female cadets are the result of greater variations in growth in them compared to women in the group of aquatic lifeguards.

When comparing the percentage of $\mathrm{FEV}_{1} / \mathrm{FVC}$ separately between men and women in the two groups (Table 4 ), it is noticeable that in women in the group of lifeguards its values are higher than in female cadets, reaching a maximum of $100 \%$ in both groups. For men, the results are better for the cadets from the Naval Academy. The presented data show that in both women and men, the Tiffeneau index is within normal limits and even exceeds the reference values in most measurements. In our opinion, the higher results of the Tiffeneau index in men and women in both groups are a prerequisite for better lung ventilation and at the same time an indicator of better functional capabilities of the respiratory system.

In conclusion, the results of a study of some basic physiological indicators of the respiratory system - FVC, $\mathrm{FEV}_{1}, \mathrm{FEV}_{1} / \mathrm{FVC}(\%)$ and related anthropometric data in persons training for marine professionals are presented. The data obtained show that all participants had normal spirometric tests. The comparison of the lung volumes and capacities between the two groups shows that in accordance with the anthropometric indicators, FVC and $\mathrm{FEV}_{1}$ are higher in the water rescue trainees in comparison with the cadets from the Naval Academy (Table 3). This trend is observed in both men and women, but in women, the maximum values of $\mathrm{FVC}$ and $\mathrm{FEV}_{1}$ were reported in female cadets, probably due to the larger variations in their growth (Table 4). The Tiffeneau index is higher in the group of naval cadets (Table 3), moving in the range of reference values and exceeding them in most measurements. Based on the existing data in the literature [4] the obtained results give us reason to conclude that the high measured values of lung volumes and capacities in the participants of both groups are an indicator of the high efficiency of lung ventilation and high functional activity of the respiratory system as a whole. As far as the functional capabilities of the respiratory system are essential for the professional activity of marine specialists, it can also be assumed that the high results of the spirometric examination in all study participants are a prerequisite for improving both their personal safety when working in the marine environment, as well as for higher efficiency and success of rescue operations.

\section{Acknowledgements}

This research was supported by MASRI - Infrastructure for Sustainable Development of Marine Research including the Participation of Bulgaria in the European Infrastructure Euro-Argo an object of the National Roadmap for Scientific Infrastructure (2017-2023) of Republic of Bulgaria.

\section{REFERENCES:}

1. Stavrev D. Marine medicine. Textbook for students of the Medical University. University Publishing House, MU - Varna. 2018.

2.Hansen HL, Jepsen JR, Hermansenb K. Factors influencing survival in case of shipwreck and other maritime disasters in the Danish merchant fleet since 1970. Safety Science. 2012 Aug; 50(7):1589-1593. [Crossref]

3. Oluseye OO, Ogunseye OO. Hu- man Factors as Determinants of Marine Accidents in Maritime Companies in Nigeria. J Marinate Res. 2016; 13(3): 61-68.

4. Levitzky MG. Pulmonary Physiology (Lange Physiology). 8th Edition. McGraw-Hill Medical, NY. April 5, 2013. [Internet]

5. Milanzi EB, Koppelman GH, Oldenwening M, Augustijn S, Aalders- de Ruijter B, Farenhorst M, et al. Considerations in the use of different spirometers in epidemiological studies. Environ Health. 2019 Apr 25;18(1):39. [PubMed] [Crossref]

6. Stanojevic S, Wade A, Stocks J, Hankinson J, Coates A, Pan H, et al. Reference Ranges for Spirometry Across All Ages. Am J Respir Crit Care Med. 2008; 177(3):253-260. [PubMed]

Please cite this article as: Stavrev D, Nikolova P, Doncheva D, Raynova V. Study of some physiological indicators of the respiratory system and related anthropometric data in persons training for marine professionals. $J$ of IMAB. 2021 Jan-Mar;27(1):3585-3588. DOI: https://doi.org/10.5272/jimab.2021271.3585

\section{Address for correspondence:}

Assoc. Prof. Dimitar Stavrev, MD, PhD

Department of Disaster medicine and marine medicine; Medical University Varna, Bulgaria

3, Bregalnitsa Str. 9002, Varna, Bulgaria.

E-mail: dgstavrev@abv.bg 